\title{
Using population-based critical care audit data to evaluate trauma outcomes
}

Authors:

Jan O Jansen, Consultant in General Surgery and Intensive Care Medicine, Departments of Surgery and Intensive Care Medicine, Aberdeen Royal Infirmary \& NRS Research Fellow, Health Services Research Unit, University of Aberdeen

Jonathan J Morrison, Specialty Registrar in General and Vascular Surgery, Academic Unit of Surgery, Glasgow Royal Infirmary, Glasgow \& Research Fellow, Academic Department of Military Surgery and Trauma, Royal Centre for Defence Medicine, Birmingham

Lorraine Smyth, Senior Analyst, Scottish Intensive Care Society Audit Group, NHS National Services Scotland, Edinburgh

Marion K Campbell, Director, Health Services Research Unit, University of Aberdeen

Correspondence to: Mr J Jansen, Ward 505, Aberdeen Royal Infirmary, Foresterhill, Aberdeen AB25 2ZN

Keywords: Trauma, trauma systems, APACHE 


\section{ABSTRACT}

Background: The analysis of mortality is an integral part of the evaluation of trauma care. When specific data are not available, general prediction models can be used to adjust for case mix. The aim of this study was to evaluate the feasibility of conducting a population-based analysis of trends in trauma mortality, using critical care audit data, and to investigate whether such data could provide a benchmark for the assessment of service reconfiguration.

Methods: Retrospective cohort study of adult trauma patients, requiring admission to a critical care unit in Scotland, 2002-2011, using nationally collected data. Results are presented as standardised mortality ratios of observed mortality divided by APACHE II predicted mortality. Tests for trends in numbers and ratios over time were performed using linear regression.

Results: 4503 patients were identified. There was a significant increase in the number of trauma patients admitted per year $(\mathrm{p}=0.011)$. The median predicted probability of in-hospital death was 7\% (interquartile range 1-13\%), against an actual mortality was $11.6 \%$. There was no significant change in the standardised mortality ratios of trauma patients $(\mathrm{p}=0.1224)$.

Conclusions: This study demonstrated the feasibility of utilising critical care unit audit data for analysing outcomes from trauma care. It also showed the potential of such an approach to establish a baseline against which to compare the impact of future service reconfiguration. In contrast to healthcare systems with regionalised trauma care, there appears to have been little change in the mortality of trauma patients requiring critical care unit admission in Scotland. 


\section{INTRODUCTION}

Trauma care remains an important public health issue. The clinical management of patients who have suffered injury often involves several specialties, with critical care medicine having a key role in coordinating the care of the most severely injured, regardless of the organ systems involved. The evaluation of risk-adjusted outcomes is an integral part of the assessment of the quality of care provided. Critical care units and networks frequently have established data collection mechanisms, with high case ascertainment. Evaluating temporal trends in this population is therefore potentially feasible and conceptually attractive.

The Scottish Intensive Care Society Audit Group (SICSAG) has been conducting a continuous national audit of patients admitted to critical care units in Scotland since 1995. The SICSAG dataset furthermore provides a complementary method of risk adjustment, using APACHE II (Acute Physiology and Chronic Health Evaluation II), a widely used scoring system and outcome prediction model for critically ill patients, ${ }^{1}$ which has also been validated in trauma patients, ${ }^{2-9}$ albeit usually in small series and single-centre studies.

The aim of this study was twofold: Firstly, to evaluate the feasibility of a populationbased analysis of temporal trends in trauma mortality, using routinely collected and risk-adjusted critical care audit data; and secondly, to determine whether such an approach could provide benchmark data against which the impact of any future reorganisation of services could be compared. 


\section{METHODS}

This is a retrospective cohort study of adult trauma patients, who required admission to a critical care unit in Scotland, between 1 January 2002 and 31 December 2011. Permission for the study was obtained from the Scottish Intensive Care Society Audit Group.

Scotland has a population of approximately 5.2 million. In 2011, there were 26 critical care units. A "critical care unit", for the purpose of this study, was defined as either an intensive care unit, or a combined intensive care/high dependency unit. Stand-alone high dependency units were excluded, because not all of these units contribute data to the SICSAG audit, and because they are heterogeneous in nature.

SICSAG maintains a national registry, which collates daily returns on all patients in intensive care, and combined intensive care/high dependency units in Scotland. Data from these returns are used to calculate an APACHE II score, by assigning numerical values to twelve clinical and biochemical parameters: Glasgow Coma Scale, temperature, mean arterial pressure, heart rate, respiratory rate, oxygenation, arterial $\mathrm{pH}$, white cell count, and serum sodium, potassium and creatinine. The sum of these individual scores, calculated from the worst values recorded within the first $24 \mathrm{~h}$ following hospital admission, comprises the Acute Physiology Score. Points are also assigned for age and the presence of pre-existing illness. Higher scores indicate greater severity of illness, with combined scores below 10 suggesting relatively mild illness, while scores above 15 indicate moderate to severe illness. Higher scores also correspond to a greater risk of death and APACHE II can be used to generate a predicted mortality rate. $^{1}$ 
SICSAG also collects some data used for the calculation of APACHE III scores, although this model is not used for outcome prediction. These data include a diagnostic classification known as "APACHE III major disease categories"10, which were used to define a "trauma patient", and subgroups, including patients with isolated head injuries, other isolated injuries, polytrauma patients with head injuries, and polytrauma patients without head injuries (table 1).

The demographic characteristics, length of stay, APACHE II data and mortality are presented using proportions for categorical and median values/interquartile ranges for continuous variables. Risk adjustment was conducted using the APACHE II severity classification. The results are presented as standardised mortality ratios (SMRs) of the observed mortality divided by the expected (APACHE II predicted) mortality. Tests for trends in numbers and SMRs over time were performed using linear regression (GraphPad Prism 6.0b, GraphPad Software, La Jolla, California, USA), testing for change in slope over time. 


\section{RESULTS}

The baseline characteristics of the study population are shown in table 2 . There were 4503 patients, $77 \%$ of whom were male, with a median age of 40 years (interquartile range 25-56 years), and some variation across the subgroups. The median critical care unit stay was two days (0-5 days), and the median hospital stay 13 days (1-26 days). The median admission APACHE II score was 13 (9-18), for a median probability of in-hospital death of 7\% (1-13\%). The actual in-hospital mortality was $11.6 \%$. The largest subgroup were patients with isolated injuries other than head injuries (39\%), followed by those who had sustained multiple injuries (36\%), and patients with isolated head injuries (26\%).

The number of trauma patients admitted to critical care units, by year, is shown in figure 1 . There has been a statistically significant increase in the total number of trauma patients ( $\mathrm{p}=0.011$ for change in slope over time), polytrauma patients with head injuries $(p=0.024)$ and patients with isolated head injuries $(p=0.036)$ admitted to Scottish critical care units. There has been no increase in the number of polytrauma patients without head injuries $(\mathrm{p}=0.285)$ or the number of patients with other isolated injuries $(\mathrm{p}=0.149)$. There has been little change in the median admission APACHE II score over time, the proportion of trauma patients (of all patients admitted to critical care units), the number of emergency hospital admissions as a result of unintentional injury, ${ }^{11}$ and a slight increase in the number of available critical care beds (table 3 ).

Figure 2 shows the SMR and 95\% confidence interval for all patients combined, patients with isolated head injuries, other isolated injuries, polytrauma patients with head injuries, and polytrauma patients without head injury, by year. There has been no significant change in the mortality of trauma patients overall $(p=0.1224$ for change 
in slope over time), patients with isolated head injuries $(\mathrm{p}=0.484)$ and polytrauma patients with associated head injuries ( $\mathrm{p}=0.8228)$, who required admission to critical care units. There has been a modest reduction in SMR for patients with other isolated injuries $(p=0.007)$ and polytrauma patients without head injuries $(p=0.029)$. 


\section{DISCUSSION}

This study demonstrates an increase in the number of trauma patients admitted to critical care units in Scotland, with a statistically significant increase in patients with head injuries, both in isolation, and as part of multi-system trauma. This rise does not appear to be explained by changes in the admission severity of illness, or the bed availability. The in-hospital mortality from trauma, of patients admitted to critical care units, also does not appear to have changed significantly over the past decade, although there is some evidence of a reduction in the mortality of patients without head injuries, isolated or as a component of multi-system injury. These changes may represent advances in the management of patients without neurological injury, including the more proactive management of haemorrhage and acute traumatic coagulopathy. In contrast, the lack of progress in reducing mortality from traumatic brain injury is well recognised. ${ }^{12}$

The results are, broadly, in keeping with the findings of the most recent Scottish Trauma Audit Group (STAG) report, which compares mortality from trauma from 1992-2002, and 2011/2012, although the inclusion criteria of the audit and our study differ. Crude in-hospital mortality for severely injured patients in the STAG audit, which demonstrates a case mix adjusted increase in the number of excess survivors per 100 patients, from 0.6 in 1992 , to 1.1 in 2002 , and 2.1 in $2012 .{ }^{13}$ However, as in our analysis, the confidence intervals associated with these estimates overlap. The differences observed may reflect variations in the inclusion criteria and, indirectly, injury severity.

In combination, the results of this study, and the Scottish trauma audit, suggest that mortality from trauma in Scotland, in the most severely injured patients, has remained 
relatively unchanged over the past decade. This is in sharp contrast to the improvements in mortality reported from other settings, following the development of trauma systems. ${ }^{14-16}$

This study also demonstrates the feasibility of using critical care unit audit data to evaluate outcomes from trauma care, on a population basis, and provide data against which the impact of any future reconfiguration of trauma services could be compared. Risk-adjustment, using APACHE II, and the separation of patients into subgroups, by diagnostic category, furthermore permits the analysis of trends in certain cohorts of patients. Such techniques may be attractive to regions without trauma registries, or where a registry has only recently been established, and where historical data is lacking. The analysis of critical care data may also complement the more common analysis of trauma registry data.

However, the use of critical care data, and APACHE II, also has intrinsic limitations. Patients who are not admitted to critical care units, either because they had injuries not requiring organ support or intensive monitoring, or because they did not survive to critical care unit admission, will not be captured. APACHE II furthermore excludes patients who die (or are discharged) within eight hours of admission, and thus even patients who survive to critical care, but die early, will be excluded. These patients are important, because they often die of exsanguination, which is potentially treatable.

Critical care audit data also does not contain information pertaining to the mechanism of injury. The use of APACHE II to adjust for risk in critically ill trauma patients is not universally accepted, ${ }^{17-20}$ although there is also a substantial body of evidence to support its use in the trauma setting. ${ }^{2-9}$ There may also be specific subgroups of trauma patients in whom the performance of APACHE II differs, ${ }^{5,18,21}$ but this applies 
to all mortality prediction models, including trauma-specific methods, such as TRISS. $^{22}$ APACHE II furthermore has some advantages over trauma-specific models, because it accounts for comorbidity.

Lastly, the use of mortality as the sole outcome measure has limitations, but at present very few units routinely collect functional outcome and quality of life data after discharge from critical care. 


\section{CONCLUSION}

In conclusion, this study adds to our understanding of the provision of trauma care in Scotland, by providing a comprehensive picture of trends over time in those most severely injured and requiring critical care. It also demonstrates the feasibility of utilising critical care unit audit data for analysing outcomes from trauma care. This type of analysis also demonstrates the potential of such an analysis to provide a baseline against which to assess the impact of any future reorganisation of services. 


\section{ACKNOWLEDGEMENTS}

We would like to thank the Scottish Intensive Care Society Audit Group (SICSAG)

for providing the data for this study. 


\section{REFERENCES}

1. Knaus WA, Draper EA, Wagner DP, Zimmerman JE. APACHE II: A severity of disease classification system. Crit Care Med 1985;13:818-29.

2. Aslar AK, Kuzu MA, Elhan AH, Tanik A, Hengirmen S. Admission lactate level and the APACHE II score are the most useful predictors of prognosis following torso trauma. Injury 2004;35:746-52.

3. Cho DY, Wang YC. Comparison of the APACHE III, APACHE II and glasgow coma scale in acute head injury for prediction of mortality and functional outcome. Intensive Care Med 1997;23:77-84.

4. Dossett LA, Redhage LA, Sawyer RG, May AK. Revisiting the validity of APACHE II in the trauma ICU: Improved risk stratification in critically injured adults. Injury 2009;40:993-8.

5. Muckart DJ, Bhagwanjee S, Neijenhuis PA. Prediction of the risk of death by APACHE II scoring in critically ill trauma patients without head injury. Br J Surg 1996;83:1123-7.

6. Rutledge R, Fakhry S, Rutherford E, Muakkassa F, Meyer A. Comparison of APACHE II, trauma score, and injury severity score as predictors of outcome in critically injured trauma patients. Am J Surg 1993;166:244-7.

7. Wong DT, Barrow PM, Gomez M, McGuire GP. A comparison of the acute physiology and chronic health evaluation (APACHE) II score and the trauma-injury severity score (TRISS) for outcome assessment in intensive care unit trauma patients. Crit Care Med 1996;24:1642-8.

8. Thanapaisal C, Saksaen P. A comparison of the acute physiology and chronic health evaluation (APACHE) II score and the trauma-injury severity score (TRISS) for outcome assessment in srinagarind intensive care unit trauma patients. $J$ Med Assoc Thai 2012;95:S25-33.

9. Hartley C, Cozens A, Mendelow AD, Stevenson JC. The APACHE II scoring system in neurosurgical patients: A comparison with simple glasgow coma scoring. Br J Neurosurg 1995;9:179-87. 
10. Knaus WA, Wagner DP, Draper EA, Zimmerman JE, Bergner M, Bastos PG, et al. The APACHE III prognostic system. Risk prediction of hospital mortality for critically ill hospitalized adults. Chest 1991;100:1619-36.

11. Information Services Division Scotland. Emergency care data tables; Available from: http://www.isdscotland.org/Health-Topics/Emergency-Care/Publications/datatables.asp?id=1219. Accessed 21 May 2014.

12. Stein SC, Georgoff P, Meghan S, Mizra K, Sonnad SS. 150 years of treating severe traumatic brain injury: A systematic review of progress in mortality. $J$ Neurotrauma 2010;27:1343-53.

13. Scottish Trauma Audit Group. Audit of trauma management in Scotland 2012 (reporting on 2011). Edinburgh: ISD; 2012.

14. Davenport RA, Tai N, West A, Bouamra O, Aylwin C, Woodford M, et al. A major trauma centre is a specialty hospital not a hospital of specialties. Br J Surg 2010;97:109-17.

15. Moore L, Hanley JA, Turgeon AF, Lavoie A. Evaluation of the long-term trend in mortality from injury in a mature inclusive trauma system. World J Surg 2010;34:2069-75.

16. Tinkoff GH, Reed JF, Megargel R, Alexander EL, Murphy S, Jones MS. Delaware's inclusive trauma system: Impact on mortality. J Trauma 2010;69:245-52. 17. Osler TM, Rogers FB, Glance LG, Cohen M, Rutledge R, Shackford SR. Predicting survival, length of stay, and cost in the surgical intensive care unit: APACHE II versus ICISS. J Trauma 1998;45:234-7.

18. Vassar MJ, Lewis FR, Chambers JA, Mullins RJ, O'Brien PE, Weigelt JA, et al. Prediction of outcome in intensive care unit trauma patients: A multicenter study of acute physiology and chronic health evaluation (APACHE), trauma and injury severity score (TRISS), and a 24-hour intensive care unit (ICU) point system. $J$ Trauma 1999;47:324-9.

19. Vassar MJ, Wilkerson CL, Duran PJ, Perry CA, Holcroft JW. Comparison of APACHE II, TRISS, and a proposed 24-hour ICU point system for prediction of outcome in ICU trauma patients. J Trauma 1992;32:490-9. 
20. Vassar MJ, Holcroft JW. The case against using the APACHE system to predict intensive care unit outcome in trauma patients. Crit Care Clin 1994;10:117-26.

21. Alvarez M, Nava JM, Rué M, Quintana S. Mortality prediction in head trauma patients: Performance of glasgow coma score and general severity systems. Crit Care Med 1998;26:142-8.

22. Demetriades D, Chan L, Velmanos GV, Sava J, Preston C, Gruzinski G, Berne TV. TRISS methodology: An inappropriate tool for comparing outcomes between trauma centers. J Am Coll Surg 2001;193:250-4. 


\section{TABLES}

Table 1: Subgroups, by APACHE III diagnostic categories

Subgroup

APACHE III unit admission diagnostic categories

\begin{tabular}{ll}
\hline Isolated head injury & Trauma - head/brain \\
Other isolated injury & Trauma - spine \\
& Trauma - face \\
& Trauma - chest \\
& Trauma - abdomen \\
& Trauma - pelvis \\
Polytrauma with head injury & Trauma - extremities \\
Polytrauma without head injury & Multiple injuries, including head injuries \\
\hline
\end{tabular}


Table 2. Baseline characteristics of study population and subgroups

\begin{tabular}{|c|c|c|c|c|c|c|c|c|c|c|}
\hline & \multicolumn{2}{|r|}{ All } & \multicolumn{2}{|c|}{$\begin{array}{l}\text { Isolated Head } \\
\text { Injury }\end{array}$} & \multicolumn{2}{|c|}{$\begin{array}{l}\text { Other Isolated } \\
\text { Injury }\end{array}$} & \multicolumn{2}{|c|}{$\begin{array}{c}\text { Polytrauma with } \\
\text { Head Injury }\end{array}$} & \multicolumn{2}{|c|}{$\begin{array}{c}\text { Polytrauma } \\
\text { without Head } \\
\text { Injury }\end{array}$} \\
\hline Number of patients ( $\%$ of total) & $\begin{array}{r}450 \\
3\end{array}$ & $(100)$ & 1156 & (26) & 1752 & (39) & 805 & (18) & 790 & (18) \\
\hline \multicolumn{11}{|l|}{ Demographics } \\
\hline Number of male patients (\%) & $\begin{array}{r}347 \\
1\end{array}$ & (77) & 960 & (83) & 1291 & (74) & 589 & (73) & 631 & (80) \\
\hline Age of patients (years), median (IQR) & 40 & $(25-56)$ & 39 & $(24-54)$ & 45 & $(28-62)$ & 35 & $(22-49)$ & 39 & $(25-53)$ \\
\hline \multicolumn{11}{|l|}{ Length of stay } \\
\hline Length of ICU stay (days), median (IQR) & 2 & $(0-5)$ & 2 & $(0-5)$ & 2 & $(0-3)$ & 5 & $(0-9)$ & 3 & $(0-7)$ \\
\hline Length of Hospital stay (days), median (IQR) & 13 & $(1-26)$ & 10 & $(0-22)$ & 11 & $(1-22)$ & 15 & $(1-29)$ & 20 & $(6-35)$ \\
\hline \multicolumn{11}{|l|}{ APACHE II score and probability of death } \\
\hline APACHE II score, median (IQR) & 13 & $(9-18)$ & 13 & $(8-19)$ & 12 & $(8-16)$ & 13 & $(9-18)$ & 12 & $(8-16)$ \\
\hline APACHE II prob of death, \%, median (IQR) & 7 & $(1-13)$ & 12 & $(3-21)$ & 6 & $(2-10)$ & 11 & $(3-19)$ & 6 & $(3-9)$ \\
\hline \multicolumn{11}{|l|}{ Mortality } \\
\hline Unit mortality (actual), n (\%) & 388 & $(8.6)$ & 156 & $(13.5)$ & 78 & $(4.5)$ & 114 & (14.4) & 40 & (5.0) \\
\hline Hospital mortality (actual), n (\%) & 483 & (11.6) & 182 & (17.2) & 120 & (7.3) & 138 & (19.2) & 43 & (5.8) \\
\hline
\end{tabular}


Table 3. Admission APACHE II score, all patients, by year, and number of emergency hospital admissions as a result of unintentional injury, by year ${ }^{11}$

\begin{tabular}{|c|c|c|c|c|c|}
\hline $\begin{array}{l}\text { Admission } \\
\text { Year }\end{array}$ & $\begin{array}{c}\text { Total number of } \\
\text { admissions to critical } \\
\text { units }\end{array}$ & $\begin{array}{l}\text { Proportion (\%) of } \\
\text { patients admitted to } \\
\text { critical care units } \\
\text { following trauma }\end{array}$ & $\begin{array}{l}\text { Number of available } \\
\text { critical care beds }\end{array}$ & $\begin{array}{l}\text { Admission APACHE II } \\
\text { score of trauma patients } \\
\text { admitted to critical care } \\
\text { units, median (IQR) }\end{array}$ & $\begin{array}{l}\text { Emergency hospital } \\
\text { admissions as a } \\
\text { result of } \\
\text { unintentional injury* }\end{array}$ \\
\hline 2002 & 6498 & 6.4 & 137 & $13(9-17)$ & \\
\hline 2003 & 9120 & 4.0 & 139 & $13(9-18)$ & \\
\hline 2004 & 9522 & 4.8 & 141 & $12(8-16)$ & 54402 \\
\hline 2005 & 8991 & 4.9 & 145 & $13(9-18)$ & 53438 \\
\hline 2006 & 9892 & 4.5 & 145 & $13(9-18)$ & 53051 \\
\hline 2007 & 10451 & 3.9 & 147 & $13(9-18)$ & 54405 \\
\hline 2008 & 10409 & 4.9 & 151 & $13(9-18)$ & 56063 \\
\hline 2009 & 9757 & 4.9 & 145 & $13(9-18)$ & 56422 \\
\hline 2010 & 9800 & 4.8 & 139 & $13(8-18)$ & 56506 \\
\hline 2011 & 10552 & 4.9 & 150 & $13(8-18)$ & 55002 \\
\hline
\end{tabular}

* To year ending 31 March. No data available for 2002 and 2003. 


\section{FIGURE LEGENDS}

Fig 1. Number of trauma patients admitted to critical care units, by year and subgroup
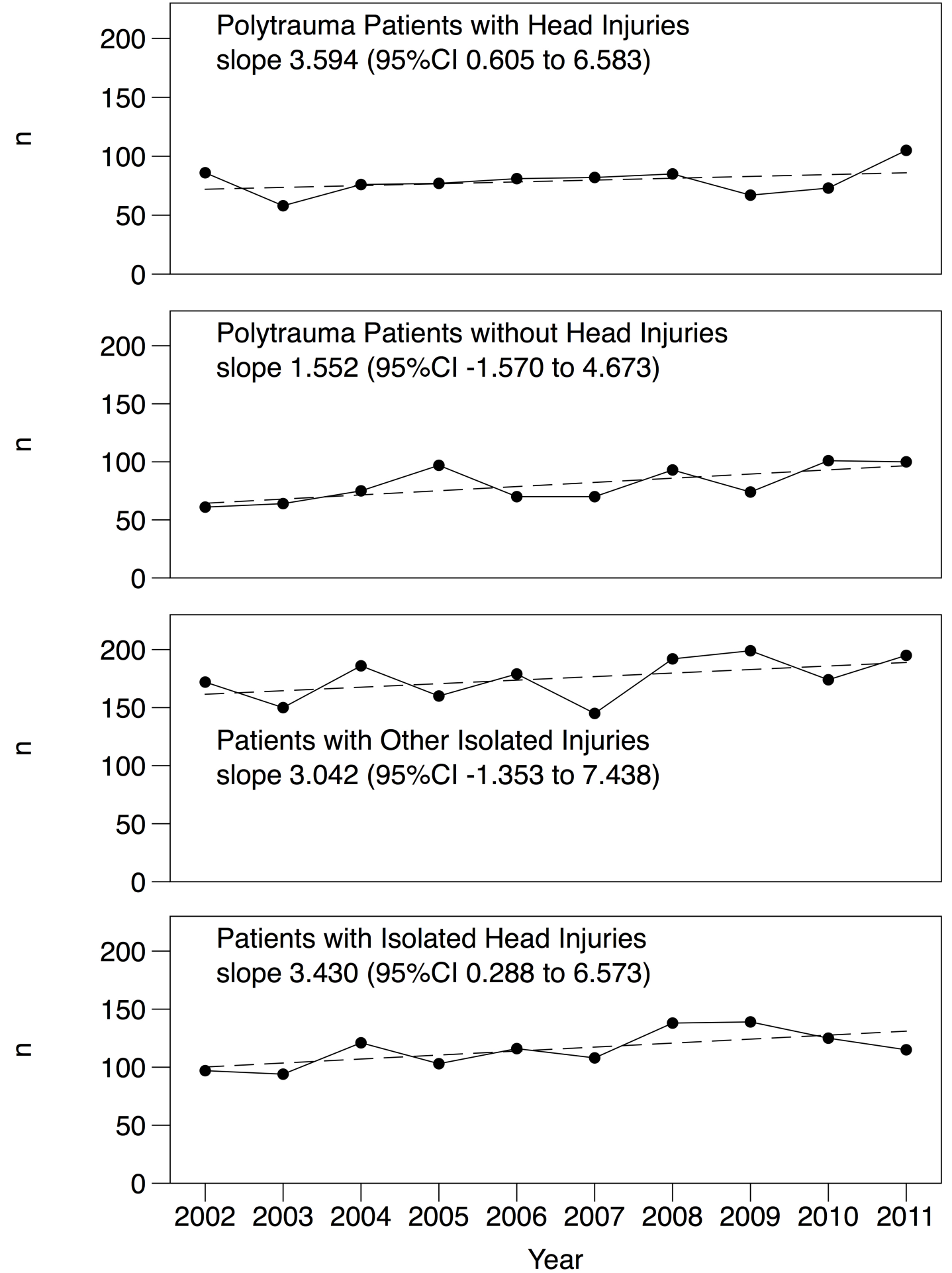
Fig 2. SMR and 95\% confidence interval, by year
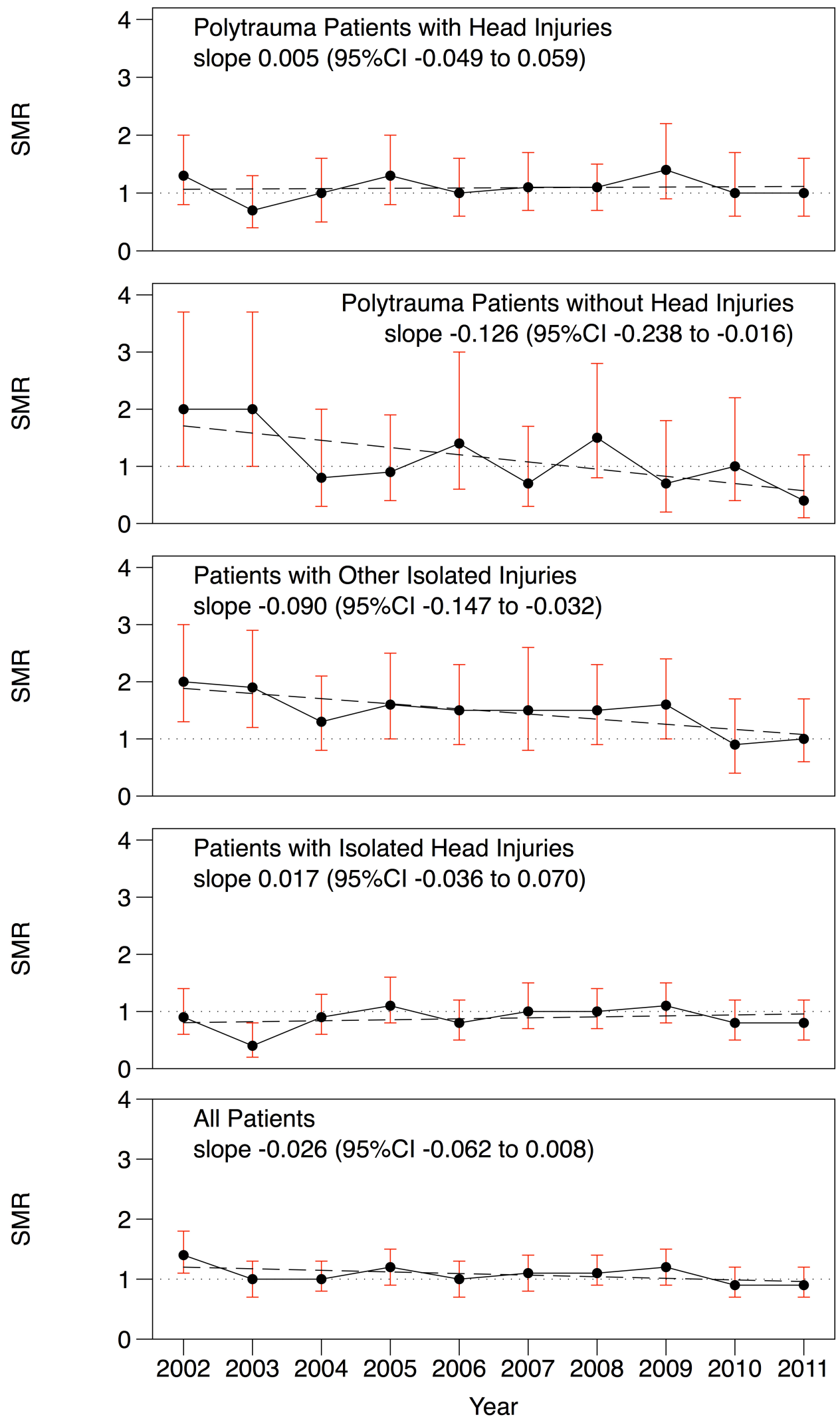